\title{
O PIBID E A ESCOLA: OS SENTIDOS DAS TECNOLOGIAS DIGITAIS NA FORMAÇÃO INICIAL DOCENTE
}

\section{THE PIBID AND THE SCHOOL: THE MEANINGS OF DIGITAL TECHNOLOGIES IN INITIAL TEACHER TRAINING}

CERVI, Gicele Maria gicele.cervi@gmail.com

FURB - Fundação Universidade Regional de Blumenau

FAVERE, Juliana

julifavere@gmail.com

FURB - Fundação Universidade Regional de Blumenau

\begin{abstract}
RESUMO Este artigo problematiza a escola e sua relação com as tecnologias digitais a partir de dados de uma pesquisa que pretendeu discutir um dos objetivos do Programa de Bolsa de Iniciação à Docência (PIBID) que é "inserir os licenciandos no cotidiano de escolas da rede pública de educação, proporcionando-lhes oportunidades de criação e participação em experiências metodológicas, tecnológicas". Foram analisadas percepções de um grupo de bolsistas de Iniciação à Docência (ID) sobre o uso das tecnologias digitais nas práticas pedagógicas. Os acordos teóricos estão centrados em Foucault (2011), Deleuze (2008), Sibilia (2012a; 2012b) e Silva (2010). Como instrumentos de coleta de dados: um questionário e materiais (diários) produzidos por IDs do PIBID que participaram de uma formação em tecnologias digitais no Laboratório Interdisciplinar de Formação de Educadores (LIFE). Infere-se que as tecnologias digitais estão presentes na vida dos escolares tanto nas escolas como nas Universidade, mas sua utilização em práticas pedagógicas está distante do cotidiano dos sujeitos pesquisados. São consideradas ferramentas que podem contribuir para os processos de ensinaraprender nas escolas. Os sujeitos reconhecem a importância das tecnologias digitais nos currículos de formação inicial, no entanto apresentam resistências quanto a sua utilização. Projetos como o PIBID, aliado ao LIFE, e o Prodocência caracterizam-se como espaços de práticas que possibilitam experimentar outros sentidos para os usos das tecnologias nos cotidianos escolares e talvez outro sentido para a escola.
\end{abstract} PALAVRAS-CHAVE: Escola. Currículo. PIBID. Tecnologias digitais.

ABSTRACT The article discusses the school and digital technologies. The research has as its goal at discussing one of the objectives of the Institutional Scholarship for Teaching Initiation Program (PIBID) which is "to insert the licensees in the daily routines of the public schools, providing them with opportunities for the creation and participation in methodological and technological experiences" coming from one experiment. The objective was to analyze the discursive practices of a group of scholars forbeginner teachers (ID) on the use of digital technologies in teaching practices. The theoretical agreements are centered on Foucault (2011), Deleuze (2008), Sibilia (2012a 2012b) and Silva (2010). The data collection instruments: a questionnaire and materials (daily) produced by a group of scholars to beginner teachers (ID) PIBID who attended a training in digital technologies at L.I.F.E. Can 
infer that digital technologies are present in the lives of students and schools, but its use in teaching practices are far from the daily life of the individuals. They are considered as tools, which can contribute for the processes of teaching-learning in schools, they voucher the importance of digital technologies in initial training curricula, however, they also present resistance as its use both in PIBID practices and as in the classes they attend at the University. Projects such as PIBID allied with LIFE and the Prodocência are characterized as spaces of dialogue which enable to experience different uses of technologies in the schools' daily routines and perhaps give another direction to the school.

KEYWORDS: School. Curriculum. PIBID. Digital Technologies.

\section{INTRODUÇÃO}

Este artigo problematiza a escola no tempo presente e sua relação com as tecnologias digitais no cotidiano da formação inicial de professores. Parte de uma pesquisa que discute um dos objetivos do Programa Institucional de Bolsas de Iniciação à Docência (PIBID) que é "inserir os licenciandos no cotidiano de escolas da rede pública de educação, proporcionando-lhes oportunidades de criação e participação em experiências metodológicas, tecnológicas e práticas docentes de caráter inovador e interdisciplinar que busquem a superação de problemas identificados no processo de ensino-aprendizagem". Os sujeitos da pesquisa foram os bolsistas de Iniciação à Docência (ID) do PIBID da Universidade Regional de Blumenau (FURB) que participaram de formação docente sobre o uso das tecnologias digitais, com ênfase na seleção e produção de materiais pedagógicos digitais.

De acordo com Sibilia (2012b), as tecnologias digitais influenciam o funcionamento das instituições educacionais e alteram as subjetividades contemporâneas. A escola, por muito tempo, teve como principal marca o disciplinamento dos corpos e estratégias de utilidade e docilidade, sinalizada pela Sociedade Disciplinar (FOUCAULT, 2011). Mudanças e deslocamentos alteram os mecanismos disciplinares, ampliando-os e reatualizando-os. Estamos vivendo, conforme Deleuze (2008), um deslocamento da sociedade disciplinar para sociedade de controle. "O homem da disciplina era um produtor descontínuo de energia, mas o homem do controle é antes ondulatório, funcionando em órbita, num feixe contínuo" (DELEUZE, 2008, p. 222-223). 
$\mathrm{Na}$ sociedade de controle os modos de ser, as regulações e as estruturas educacionais são alteradas. Um dos ganhos da contemporaneidade foi o modo como julgamos as coisas, o parâmetro era a verdade, hoje, a regra é lidar com as incertezas (MOSÉ, 2014). A escola passa dos tempos das certezas para as promessas e para as incertezas (CANÁRIO, 2006; MOSÉ, 2014). Nela muitas rotinas são alteradas, se uma das questões centrais era a letra bonita, caderno de caligrafia, postura nas carteiras e momentos como tirar ou deixar o boné, na escola contemporânea, uma das questões parece ser tirar ou deixar o celular, o tablet e outros dispositivos móveis. Uma das questões que norteiam a escola é o que fazer com as tecnologias digitais.

A inserção das tecnologias digitais em diferentes campos da sociedade, inclusive nas instituições de ensino, altera o espaço, o tempo, a relação entre as pessoas, o modo de comunicação e o acesso à informação, uma vez que a "interação global é rápida, por meio da mídia e da tecnologia da comunicação" (VEEN; VRAKKING, 2009, p. 21). Os jovens do século XXI aprendem em redes. O modo de aprender, conviver e constituir as instituições sociais apresenta outras características. A escola, como outras instituições, altera-se e é alterada, na qual o professor depara-se com 'outros' modos de aprender dos estudantes e, para isso, compreende-se como necessário discutir/explorar/vivenciar/experimentar na formação inicial o uso das tecnologias digitais como estratégias para ensinar/aprender.

As tecnologias digitais, por um lado, podem apenas substituir uma tecnologia já em uso, como o quadro, e ter por base uma metodologia tradicional, nas palavras de Freire (2014) "uma educação bancária" e, nesse sentido, não alteram os processos de aprendizagem e as práticas na escola. Por outro lado, podem ser utilizadas como uma inovação pedagógica, com o foco na aprendizagem, com metodologias que considerem o estudante como coautor da construção do conhecimento. De um modo ou de outro, as tecnologias digitais estão na sociedade e na escola e alteram os currículos e suas organizações.

Neste artigo, discutiremos a utilização das tecnologias digitais no contexto do PIBID, os sentidos das tecnologias digitais a partir do estudo e problematização de autores como Michel Foucault (2011) e Gilles Deleuze (2008) para pensar esse 
tempo, Pierre Lévy (2011), Paula Sibilia (2012a 2012b), Viviane Mosé (2014), Rui Canário (2006) e Marco Silva (2010), para pensar a escola e as tecnologias digitais. $E$, quem sabe, pensar um outro sentido para a escola do século XXI.

A partir dos dados da pesquisa, pode-se inferir que as tecnologias digitais estão na vida dos acadêmicos e nas escolas, mas não estão presentes nas práticas pedagógicas na Universidade e distantes das escolas de educação básica. Os bolsistas reconhecem essa ausência e apontam a necessidade de utilizar as tecnologias digitais nas práticas pedagógicas, mas pouco estudam e quase nada discutem/vivenciam/experimentam essas possibilidades na sua formação inicial.

Interessa discutir a escola e as tecnologias digitais no sentido de pensá-las como possibilidades de criação de resistências, mas também de pensar em que medida elas ampliam as possiblidades de controle. Lembrando Deleuze

acreditar no mundo significa principalmente suscitar acontecimentos, mesmo pequenos, que escapem ao controle, ou engendrar novos espaçostempos, mesmo de superfície ou volume reduzido. É o que você chama de pietás. É ao nível da tentativa que se avaliam a capacidade de resistência ou, ao contrário, a submissão a um controle (2008, p.218).

$E$, nesse sentido, em que medida as tecnologias são possibilidades de submissão ou de inovação nos contextos escolares? Pois, como afirma Mosé (2014), ensinar não pode ser transmitir conhecimento, mas provocar interesses e dúvidas, desenvolver métodos de pesquisa e de filtragem e seleção de dados, de ordenação de conteúdos, de construção da argumentação. Eis o interesse maior deste artigo. Quais os sentidos das tecnologias digitais na escola? Qual o sentido da escola?

\section{ESCOLARIZAÇÃO, TECNOLOGIAS DIGITAIS E PIBID}

A escola foi uma fonte de "tempo livre", a tradução mais comum da palavra grega skolé. A escola era uma fonte de conhecimentos e experiências disponibilizada como um "bem comum". A partir da segunda metade do século $X X, a$ existência da escola foi posta em questão (MASSCHELEIN; SIMONS, 2013), pois tornou-se uma instituição refratária ao que acontece ao seu redor. Aquilo que 
acontece fora dela, em geral, não interessa e ainda mais, perturba um contexto já cristalizado de regras rígidas e imutáveis. Dentre essas questões estão as práticas pedagógicas que não permitem conexão com o mundo que os estudantes estão experimentando, nem para problematizá-lo, nem para explorar outras formas de aprender.

Conforme Canário (2006), o século XX é marcado por três fatores: a hegemonia da forma escolar, a naturalização e a persistência da configuração organizacional e do estabelecimento de ensino e as mutações sofridas pela instituição escolar. As mutações foram de um modelo de certezas para um modelo de promessas e, finalmente, para um modelo marcado pela incerteza.

A escola em sua configuração tradicional foi, e ainda é, organizada na "lógica arborescente". Nessa lógica é possível identificar a organização em sistemas hierárquicos, em que as conexões são preestabelecidas, ou seja, transmitem-se informações de uma unidade para outras que apenas recebem (DELEUZE; GUATTARI, 1995). Essa distribuição unilateral é representada pelo tronco da árvore.

A organização das escolas ainda tem como base uma divisão do tempo (aula de 50 minutos), dos espaços (salas de aula), do agrupamento dos estudantes (turmas) e dos saberes (disciplinas) aos quais corresponde determinada divisão entre os professores. Essa organização atende a uma concepção cumulativa do conhecimento, no qual o currículo corresponde a um menu de informações transmitidas em doses sequenciadas sustentadas pela lógica da repetição, numa relação pedagógica de cunho autoritário. Uma lógica uniforme e estável contribuindo para que as escolas sejam semelhantes ao que "naturaliza" a forma e para desarmar professores e estudantes de uma compreensão crítica do seu modelo (CANÁRIO, 2006). Afinal, todas ou quase todas são assim.

De acordo com Sibilia (2012a), as tecnologias digitais afetaram o funcionamento basilar na escola. Sua estrutura, desde sua invenção, privilegiava a disciplina, as regras e o controle dos comportamentos e atitudes, desenvolvendo determinadas habilidades e aptidões afinadas com o propósito da época. Outra característica da escola pautou-se, e ainda está presente, na repetição da informação, em que conteúdos são transmitidos sem a discussão e construção de argumentação por parte dos estudantes. O professor, nesse contexto, atua pela 
lógica linear de transmissão e separação da emissão e recepção (SILVA, 2010).

Ao se instaurar sob a égide da "cultura letrada" a escola tornou-se fortemente marcada pelos meios de comunicação audiovisuais (SIBILIA, 2012a). Segundo Silva e Claro (2007), na Sociedade Industrial a informação era controlada pela imprensa, rádio e televisão, na qual se configurava o modelo um-todos, ou seja, a informação pertencia a um local/ mídia específica e era distribuída para todos. O modo de informar e comunicar se expandiu e modificou-se com a internet. Pode-se indicar que houve uma transição do modelo um-todos, para todos-todos ou faça-vocêmesmo (SILVA, 2010). A internet nos permite produzir materiais, como blogs, páginas nas redes sociais ou mesmo interferir em algo já produzido, tecendo comentários sobre reportagens nos jornais digitais ou em vídeos postados. No contexto escolar, o receptor - o aluno - que por muito tempo não tinha 'luz', hoje é considerado um usuário, ou ainda coautor da produção dos saberes e de seu aprendizado.

É neste sentido que Feitosa, Souza e Andrade (2013, p. 01) apontam que com os recursos audiovisuais é possível "a explanação de um novo conteúdo, para ilustrar situações que estejam distantes da realidade atual, entre outros, como também desenvolver o senso crítico do alunado em relação à veracidade das informações obtidas através da mídia"

A sociedade, suas informações e comunicação estão dispostas em rede, 0 que indica que as informações são multidirecionais, isto é, não estão concentradas em um único local ou mídia, mas provêm de inúmeras pessoas, grupos, movimentos e instituições sociais. O site é um exemplo da possibilidade de manipulação e criação de informações, pois, na maioria dos casos, "pressupõe imersão e participação-intervenção do indivíduo" (SILVA, 2010, p. 82).

Pode-se indicar um novo espaço com pretensão universal de comunicação e informação, o ciberespaço, que surge com a comunicação global dos computadores pela internet. Nesse espaço, há a possibilidade de pensar a cibercultura nos movimentos da escola e outras instituições sociais, que, conforme Lévy, é definida pelo "conjunto de técnicas (materiais e intelectuais), de práticas, de atitudes, de modos de pensamento e de valores que se desenvolvem juntamente com o crescimento do ciberespaço" (2011, p. 17). 
A prática da cibercultura da escolarização não tem a pretensão de resolver os problemas sociais, culturais e educacionais; mas reconhecer o crescimento do ciberespaço e entendê-lo como um novo espaço de comunicação (LÉVY, 2011).

A expansão da comunicação e informação por meio das tecnologias digitais, na contemporaneidade, traz desafios para as instituições sociais, especialmente para as escolas. A internet contribuiu para que acontecessem modificações nos modos de pensar, agir e aprender, pois ela, "como artefato cultural é produtora e produto de novos modos de agir, de comunicar-se, bem como de novas práticas de linguagens, pertencendo definitivamente à cibercultura" (GOMEZ, 2010, p. 67). E, em muitas escolas, continuam ensinando como se as tecnologias digitais não fizessem parte desse mundo, mas, "as subjetividades se constroem nas práticas cotidianas de cada cultura, e os corpos também se esculpem nesses intercâmbios" (SIBILIA, 2012a, p.10).

Sibilia (2012a) nos indica atualmente que outras habilidades e aptidões são requeridas na escolarização, pois estão afinadas com o propósito da época, desde sua criação. O estímulo hoje perpassa pela criatividade e prazer nas atividades laborais, além de originalidade e capacidade de mudanças (SIBILIA, 2012a), como "também são bem cotadas a livre iniciativa, a motivação, o empreendedorismo, e a vocação proativa" (SIBILIA, 2012a, p. 203).

O contexto escolar é um espaço privilegiado para o diálogo, para a intervenção por parte dos estudantes. Para Silva "processo de produção de sentido que torna o aprendiz ou interagente capaz de construir seu próprio percurso de aprendizagem, e que ofereça a este potencialidades de produção de sentido reais" (2010, p. 188). Pode haver, assim, modificações na prática pedagógica e comunicacional na sala de aula, em que a participação é modificação e interferência na mensagem, a comunicação é produção conjunta da emissão e recepção e o emissor/professor possibilita múltiplas redes articulatórias: conexões, associações e significações (SILVA, 2010).

Nesse contexto, o estudante é coautor do seu aprendizado. Não tem mais sentido o estudante passivo que só recebe e o professor que só transmite informações e conhecimentos. Esse modelo de educação escolar, comunicação e lógica da distribuição (SILVA, 2010) encontra-se esgotado, embora persista em 
muitas práticas pedagógicas.

Segundo Brasil, "As crianças são mais rápidas, impacientes, 'multitarefas', 'multitelas', sempre prontas para fazer, produzir algo diferente e com dificuldade de sistematizar, de formular novas sínteses" (2005, p. 98). Ao contrário de criticar essa geração, podemos tentar entendê-la e criar estratégias que contribuam com o que já sabem e com o que ainda não sabem. É nesse sentido que podemos criar um caminho de comunicação entre professor e estudantes para "focar mais a relação afetiva, gostar dos alunos como eles são, chamá-los para participar, aproveitar todo o potencial para motivá-los, valorizá-los, incentivá-los, surpreendê-los" (BRASIL, 2005, p. 98).

A comunicação e a interação é o modo de o professor dispor aos estudantes um campo de possibilidades, de caminhos que permitem significações livres e plurais (SILVA, 2010). Desse modo, o estudante "não está mais reduzido a olhar, ouvir, copiar e prestar contas. Ele cria, modifica, constrói, aumenta e, assim, torna-se coautor". As tecnologias digitais são um meio em que é possível explorar diferentes linguagens como imagens, falas, música, escrita e outros. É possível estar submetido a maior diversidade de estímulos visuais, auditivos, táteis, gustativos. Os estudantes constituem suas subjetividades não mais nos meios disciplinares, mas na experiência cotidiana muito mais midiática e mercantil (SIBILIA, 2012a). Mas é preciso ressaltar que as tecnologias digitais são apenas um meio e que existem outros.

Para Deleuze (2008), a sociedade de controle implanta um regime de vida inovador, apoiado nas tecnologias eletrônicas e digitais, uma organização social baseada no capitalismo mais dinâmico, regido pelo excesso de produção e pelo consumo exacerbado, pelo marketing e pela publicidade, pelos fluxos financeiros em tempo real e interconexão em redes globais de comunicação. "Estamos entrando nas sociedades de controle, que funcionam não mais por confinamento, mas, por controle contínuo e comunicação instantânea" (2008, p.216).

Para essa sociedade, diferente da sociedade disciplinar, as exigências para os estudantes parecem encaminhar na direção de vivências e experiências que contribuam para uma formação que permita selecionar, diante de tanta informação disponível, criar, a partir de ampliação de seu repertório cultural e posicionar-se, 
diante de diferentes modos de comunicação e informações, para além dos modos tradicionais de ensino. Os recursos tecnológicos digitais podem contribuir nesse processo possibilitando a exploração de conhecimentos e a interação. Como afirma Mosé

O século XXI caminha na direção a uma escola na qual o aluno seja ouvido e considerado. Uma escola para o aluno, dirigida para o seu desenvolvimento, tendo como alvo a vida em todas as suas dimensões. Uma escola na qual a arte, a filosofia, a ética estejam presentes que não precisem de cinquenta minutos na grade curricular; ou melhor, uma escola que não tenha grade curricular, mas temas, assuntos, questões. Uma escola que não se acovarde diante das perguntas mais difíceis, como a morte, o tempo, a dor, a violência, a discriminação social, étnica, religiosa, mas que construa espaços nos quais essas questões sejam discutidas, pensadas. Enfim, uma escola viva, alegre, corajosa, sempre aberta a novas questões (2014, p.83-84).

$\mathrm{Na}$ contemporaneidade, os modos de agir, pensar e aprender adquirem outros modos de construção. É tempo de rizomas, de fluxos e de conexões. Os modos de conhecer, ler e comunicar-se estão pautados também na lógica de rede. De acordo com Silva, o novo paradigma tecnológico "liberta o usuário da lógica unívoca, da lógica da distribuição arborescente, próprias da mídia de massa e dos sistemas de ensino predominantes no século XX" (2009, p. 29). De encontro à lógica arborescente está a metáfora do hipertexto (SILVA, 2010), que é representada pela ideia de rede, ou ainda de rizoma, as conexões não são preestabelecidas, ou seja,

[...] Contra os sistemas centrados, de comunicação hierárquica e ligações preestabelecidas, o rizoma é um sistema acentrado, não hierárquico e não significante, sem General, sem memória organizadora ou autômato central, unicamente definido por uma circulação de estados (DELEUZE; GUATTARI, 1995, p. 25).

É nesse sentido que Silva apresenta alguns desafios ao professor diante de uma leitura e comunicação interativa na escolarização, como: saber lidar com hipertexto e converter-se em um formulador de problemas, que possibilita o diálogo e não substituição, mas articulação na construção do conhecimento hipertextual com os processos de leitura lineares (SILVA, 2010). De modo geral, altera o papel e a 
atuação do professor, pois a leitura textual não vem para substituir o ensino linear, mas para potencializar o aprendizado. Como o hipertexto é produzido na internet, muitas vezes coletivamente pelos usuários, há modificação na relação leitor-escritor, na qual o "leitor-navegador não é um mero consumidor passivo, mas um produtor do texto que está lendo, um coautor ativo, capaz de ligar os diferentes materiais disponíveis, escolhendo seu próprio itinerário de navegação" (COSTA, 2000, p.4). O leitor do hipertexto escolhe o melhor caminho da leitura e do conteúdo, de acordo com suas necessidades e seus interesses. Para Soares, "A tela, como novo espaço de escrita, traz significativas mudanças nas formas de interação entre escritor e leitor, [...] a hipótese é de que essas mudanças tenham consequências sociais, cognitivas e discursivas" (2002, p.146).

Vale lembrar que devido à aceleração do acesso às informações e sua quantidade, pode existir a diminuição da profundidade de compreensão das informações pelos leitores; "a fartura dos textos inseridos nesse ambiente pode, muitas vezes, levar a um estreitamento do raciocínio e do pensamento por interferência da própria forma de uso (veloz, fugaz, etc.) dessas ferramentas de navegação" (MAGNABOSCO, 2009, p. 91). O que pode gerar também dispersão, diante de tantos links, em que o leitor, por um leve descuido, já não se localiza mais em sua leitura inicial, perdendo-se no mundo da internet.

Dentre os movimentos da escola, e nelas as tecnologias digitais, temos o PIBID que é um programa da CAPES, o qual tem seus objetivos definidos no Art. $4^{\circ}$ da Portaria no 96 de 18/07/2013:

I - incentivar a formação de docentes em nível superior para a educação básica;

II - contribuir para a valorização do magistério;

III - elevar a qualidade da formação inicial de professores nos cursos de licenciatura, promovendo a integração entre educação superior e educação básica;

IV - inserir os licenciandos no cotidiano de escolas da rede pública de educação, proporcionando-lhes oportunidades de criação e participação em experiências metodológicas, tecnológicas e práticas docentes de caráter inovador e interdisciplinar que busquem a superação de problemas identificados no processo de ensinoaprendizagem;

V - incentivar escolas públicas de educação básica, mobilizando seus professores como coformadores dos futuros docentes e tornando-as protagonistas nos processos de formação inicial para o magistério; 


\begin{abstract}
VI - contribuir para a articulação entre teoria e prática necessárias à formação dos docentes, elevando a qualidade das ações acadêmicas nos cursos de licenciatura;

$\mathrm{VII}$ - contribuir para que os estudantes de licenciatura se insiram na cultura escolar do magistério, por meio da apropriação e da reflexão sobre instrumentos, saberes e peculiaridades do trabalho docente.
\end{abstract}

O PIBID é um programa de formação que tem contribuído para criar coletivos ou redes de formação nas Universidades e nas escolas de educação básica. Um programa que possibilita diálogos entre a escola de educação básica e a Universidade. Nos espaços do PIBID muitas discussões, trabalhos, intervenções, reflexões, pesquisas e problematizações estão acontecendo, possibilitando o pensar em uma escola viva, em uma escola para esse tempo, corajosa e aberta para as questões dos jovens. Mas, por outro lado, lida com corpos disciplinados, corpos escolarizados, corpos que não foram definidos magicamente, mas fabricados e, lembrando Foucault (2011, p.172), "O indivíduo é sem dúvida o átomo fictício de uma representação 'ideológica' da sociedade; mas é também uma realidade fabricada por essa tecnologia específica de poder que se chama 'disciplina'”.

Projetos como o PIBID são espaços/tempos para repensar os sentidos das tecnologias digitais e o sentido da escola que se constitui num ambiente enfraquecido, onde o saber e o desejo de aprender estão distantes. Um espaço que, segundo Canário (2006), precisa ser reinventado, um espaço vivo em que os processos de mudança são ecológicos: a escola e os seus atores mudam e por interação recíproca. Para superar a forma escolar centrada no ensinar e transferir para o aprender o eixo central das preocupações; significa considerar a experiência de quem aprende como principal recurso para sua formação; significa em termos da produção do saber, privilegiar as perguntas por oposição às soluções; significa reconhecer o valor do erro nos processos de aprendizagem (CANÁRIO, 2006).

A pedagogia ajudou a dar forma e corpo a essa escola como a conhecemos. Formulou programas, ideias, diretrizes que foram disciplinando cada um de nós a pensar a escola desse jeito. Acredita-se que na medida em que vamos conhecendo quanto escolarizado é o nosso corpo, é que podemos pensar, aprender, ler, conhecer e conviver com o mundo de outras formas. A formação e a pesquisa tiveram a intenção de compreender/vivenciar/experimentar/pensar sobre os sentidos 
que as tecnologias digitais têm para os bolsistas ID, sob a lógica de experienciar. É isso que uma oficina oferece, uma experimentação para pensar, ler e conviver com o mundo de outras formas. Um modo de repensar outras formas de lidar os processos formativos da escolarização.

Interessa neste artigo discutir e problematizar o Inciso IV - "inserir os licenciandos no cotidiano de escolas da rede pública de educação, proporcionandoIhes oportunidades de criação e participação em experiências metodológicas, tecnológicas e práticas docentes de caráter inovador e interdisciplinar que busquem a superação de problemas identificados no processo de ensino-aprendizagem". A questão específica está em torno da utilização das tecnologias digitais como possibilidades de criar e participar de experiências para superar problemas identificados nas escolas, dentre eles a falta de conexão com o mundo ao redor. Será esse um dos objetivos possíveis? Quais os sentidos das tecnologias digitais nas práticas pedagógicas para os bolsistas de Iniciação à Docência (ID)?

O PIBID tem esse compromisso para superar a forma escolar centrada no ensinar. A formação tem a intenção explorar e vivenciar outros sentidos para as tecnologias digitais na escola e para a escola. Estamos trabalhando com a formação de professores para uma escola que desejamos, que tenha outro sentido.

\section{PRÁTICAS DISCURSIVAS: OS SENTIDOS DAS TECNOLOGIAS DIGITAIS PARA OS BOLISTAS ID NUMA FORMAÇÃO DOCENTE}

Considera-se que um dos espaços principais para discussão, diálogos e aprendizagens sobre as tecnologias digitais é a formação inicial. Por esse motivo, desenvolveu-se essa pesquisa sobre uma formação docente e o uso das tecnologias digitais com o foco na seleção e produção de materiais pedagógicos digitais. Também se parte do pressuposto de que é preciso experimentar e a partir da experimentação pensar possibilidades. Nesse espaço de formação docente foi possível explorar e pesquisar o uso das tecnologias digitais na escola. A intenção é, a partir de vivências com as tecnologias, através de oficinas, compreender os sentidos que os estudantes atribuem às tecnologias nos cotidianos escolares.

Os sujeitos da pesquisa foram licenciandos envolvidos com o PIBID que 
realizaram a formação, num total de 90 bolsistas. Reforçando o que já descrito neste artigo, o PIBID é um Programa da CAPES - Coordenação de Aperfeiçoamento de Pessoal de Nível Superior e tem como objetivo no Art. 4 da Portaria $n^{\circ} 96$ de 18/07/2013 Inciso IV:

a inserção dos licenciandos no cotidiano das escolas das redes públicas visando proporcionar-lhes oportunidades de criação e participação em experiências metodológicas, tecnológicas e práticas docentes de caráter inovador e interdisciplinar que busquem a superação de problemas identificados no processo de ensino-aprendizagem.

Um dos objetivos da oficina foi que os licenciandos realizassem experimentações e produções inovadoras (com as tecnologias digitais) visando qualificar sua prática docente.

A oficina foi realizada no LIFE - Laboratório Interdisciplinar de Formação de Educadores - que tem como principal finalidade possibilitar a produção de material didático utilizando recursos tecnológicos atualizados. É direcionado aos estudantes dos cursos de licenciatura e das escolas de educação básica, e pode também ser utilizado pelo docente como espaço de ensino e aprendizagem para as aulas dos cursos de licenciatura da FURB. Dentre os objetivos específicos do Projeto LIFE apresenta-se "o incentivo à produção de materiais pedagógicos interdisciplinares para utilização com os estudantes estimulando a criatividade e interesse para melhoria da educação básica".

A oficina gerou muitos dados, dentre eles, destacam-se como instrumentos os registros construídos no momento da formação docente e um questionário. Dos registros, coletaram-se os diários de aula e neles somente as percepções da formação, construídos no último encontro. Dentre as categorias selecionadas estão: as produções realizadas, dificuldades encontradas e modos de utilização das tecnologias digitais.

A formação foi distribuída em três encontros. O primeiro em formato de minicurso, para discutir sobre as tecnologias digitais com base em autores de referência, bem como conhecer e explorar o laboratório LIFE. No segundo encontro houve um momento de planejamento e construção dos materiais pedagógicos digitais. E no terceiro encontro a finalização dos materiais construídos e a sua 
socialização no grande grupo.

Em relação ao número de participantes, estavam assim distribuídos: 24 bolsistas do curso de Educação Física, 18 de Ciências Biológicas, 14 de Letras, 17 de História e 17 do grupo Interdisciplinar. O resultado final dos encontros, com estudos e oficina, resultou na produção de diferentes materiais pedagógicos digitais produzidos com recursos tecnológicos diversos como e-book, blog, vídeo, entre outros. Os dados gerados para este artigo tiveram como foco o segundo momento que foi de oficina.

No registro Diário de Aula relataram-se as discussões e a compreensão individual acerca das tecnologias digitais. Alguns registros desse momento foram utilizados como dados da pesquisa e destacam-se a seguir:

Quadro 1 - Registros dos Diários de Aula produzidos pelos bolsistas PIBID

\begin{tabular}{|c|c|}
\hline ESTUDANTE & REGISTROS \\
\hline 1 & $\begin{array}{l}\text { As tecnologias trazem mais rapidamente a realidade e com mais eficiência as } \\
\text { respostas dos questionamentos estudantis, mesmo não sendo tão utilizados como } \\
\text { deveriam. } \\
\text { A tecnologia está presente hoje para somar na educação, sendo muito útil, pois esta } \\
\text { dá suporte para o conhecimento, pois a sociedade hoje está em rede, isso quer } \\
\text { dizer, ninguém sabe mais do que ninguém, todos nós somos somadores do saber, } \\
\text { formadores de opinião. } \\
\text { A interatividade está fortemente presente nas vidas de todos nós. Hoje a internet } \\
\text { nos fornece informações em uma velocidade absurda, sendo que as crianças tanto } \\
\text { fora quanto dentro da escola fazem parte dessa tecnologia, necessitando, assim, de } \\
\text { uma orientação diferenciada, pois esta criança é diferenciada. }\end{array}$ \\
\hline 2 & $\begin{array}{l}\text { No "ontem" estávamos no sistema passivo, e hoje nos encontramos no pós-passivo, } \\
\text { não somente ouço, mas escrevo, e o mundo interage com minhas produções! } \\
\text { " "Sem a problematização não há instrumento que dê jeito!" } \\
\text { ldeia do uso das tecnologias na escola: usar esta tecnologia para pesquisar com as } \\
\text { próprias crianças na escola. }\end{array}$ \\
\hline 3 & stão dando aula; possuem jeitos de pensar diferentes. \\
\hline 4 & $\begin{array}{l}\text { Hoje em dia percebemos que a tecnologia está mais presente na sala de aula e o tipo } \\
\text { de comunicação mudou. Percebemos também que a escola tem custado a } \\
\text { acompanhar o ritmo das tecnologias da sociedade. Por isso a atualização dos } \\
\text { modos didáticos dos professores é imprescindivel ao aprendizado da nova geração. } \\
\text { Necessitamos de pessoas com visão inovadora e pragmática, para que a escola se } \\
\text { torne um lugar não apenas mensageiro, mas disseminador de ideias. }\end{array}$ \\
\hline 5 & $\begin{array}{l}\text { Como as mudanças das décadas, mudam as gerações. A rapidez como as } \\
\text { informações chegam rapidamente na nossa casa, ou no dia a dia. } \\
\text { Informações rizomáticas, um novo contexto de ver a educação, a forma como é } \\
\text { compartilhada a informação. Com a tecnologia, a interação aluno-professor torna-se } \\
\text { mais dinâmica, o aluno muitas vezes já vem com um pré-conhecimento do assunto, } \\
\text { tornando o ensino mais rentável. } \\
\text { Usar a tecnologia para produzir e ler mais. }\end{array}$ \\
\hline
\end{tabular}

Fonte: bolsistas PIBID. 
Conforme Quadro 1, com os registros do encontro e de as vivências na escola os bolsistas percebem o desafio do professor diante do aparato tecnológico, pois os estudantes que se encontram nas instituições escolares estão cada vez mais imersos no universo das tecnologias digitais. Percebem a presença das tecnologias digitais na sala de aula e no cotidiano das pessoas e deixam isso bem evidente. Como também percebem nas tecnologias digitais uma possibilidade de produzir mais, de criar, de pensar de forma diferente e conviver com diferentes gerações em um mesmo espaço escolar, conforme E3, "Todas as gerações estão dando aula; possuem jeitos de pensar diferentes". Conforme Sibilia (2002, p. 12), a "transição para um outro tipo de formação social, caracterizada por um novo regime de poder e por tecnologias inovadoras de formatação dos corpos e das subjetividades".

Os bolsistas pesquisados, conforme quadro 1 , indicam que a repetição de informação não está mais propícia aos objetivos educacionais e do perfil dos estudantes e profissionais da contemporaneidade. Ao encontro da ideia, o E2 indica que "No 'ontem' estávamos no sistema passivo, e hoje nos encontramos no póspassivo, não somente ouço, mas escrevo, e o mundo interage com minhas produções! [...] Sem a problematização não há instrumento que dê jeito!". Lembrando Canário, a escola está imersa no contexto da imprevisibilidade, pois "passou de um contexto de certezas, para um contexto de promessas, inserindo-se, atualmente, em um contexto de incertezas" (CANÁRIO, 2006, p. 16). É nesse contexto que a escola precisa construir nova legitimidade.

Palavras como mudança e inovação percorrem os espaços escolares e práticas discursivas desta pesquisa, como aponta o E1:

"A interatividade está fortemente presente nas vidas de todos nós. Hoje a internet nos fornece informações em uma velocidade absurda, sendo que as crianças tanto fora quanto dentro da escola fazem parte dessa tecnologia, necessitando, assim, de uma orientação diferenciada, pois esta criança é diferenciada".

Mas, o que seria desejável mudar? Canário (2006) orienta para três caminhos para mudanças no trabalho escolar: estimular o gosto pelo trabalho intelectual de aprender, aprender pelo trabalho e exercer o direito à palavra. 
Os relatos dos bolsistas apontam para a necessidade de mudança na escola com a inserção das tecnologias digitais e a necessidade de reestruturar as metodologias de ensino - ainda muito enraizadas em práticas pedagógicas tradicionais - possibilitando conteúdos mais interativos, de acordo com E4:

"Hoje em dia percebemos que a tecnologia está mais presente na sala de aula e o tipo de comunicação mudou. Percebemos também que a escola tem custado a acompanhar o ritmo das tecnologias da sociedade. Por isso a atualização dos modos didáticos dos professores é imprescindível ao aprendizado da nova geração".

Outro aspecto a destacar é quanto às palavras "velocidade" e "rapidez" apontada pelos bolsistas. Se as tecnologias estão aí para acelerar nossa relação com o tempo, antecipando o futuro de modo que ele se torne imediatamente presente, convém refletir o sentido que estamos atribuindo ao tempo. Por que não podemos aprender mais demoradamente? Será que os sentidos das tecnologias digitais passam por acentuar a rapidez, velocidade e ocupação? Lembrando Deleuze "O controle é de curto prazo e de rotação rápida, mas também contínuo e ilimitado, ao passo que a disciplina era de longa duração, infinita e descontínua. $O$ homem não é mais o homem confinado, mas o homem endividado" (2008, p.224).

Conforme os bolsistas pesquisados, as tecnologias digitais estão presentes na vida em sociedade. O E5 traz esse indicativo: "A rapidez como as informações chegam rapidamente na nossa casa, ou no dia a dia." Sua função na escola é fazer com que os professores se aproximem dos estudantes da educação básica e utilizálas como modo de potencializar a interação, comunicação e a produção com/no mundo.

Além do Diário de Aula, foram selecionados e analisados registros do questionário aplicado no último encontro aos bolsistas com base em duas categorias de análise: 1) suas percepções da formação, acerca das produções desenvolvidas, e 2) dificuldades encontradas.

Alguns registros na primeira categoria de análise apontam:

- o alcance dos resultados pretendidos, tanto na elaboração como utilização do material nas escolas com os estudantes da educação 
básica;

- a importância da utilização das tecnologias digitais para registrar as atividades e o cotidiano escolar;

- os grupos que já tinham experiência com produção de vídeo tiveram facilidade na produção;

- os materiais produzidos serão úteis para divulgarem para outras pessoas/comunidade;

- a construção de materiais digitais em grupo requer certo nível de organização, liderança, dinâmica de grupos por parte dos estudantes;

- todos buscaram meios diferentes de interagir com os estudantes e tornar as aulas menos monótonas com novas metodologias como a utilização de recursos lúdicos e tecnológicos, entre outros.

Aproximando os registros dos Diários e a primeira categoria de análise, podese inferir que os bolsistas pesquisados trabalharam na construção de um material pedagógico digital adequado a esse tempo e ao perfil dos estudantes das escolas, considerando o envolvimento destes em suas propostas. Os sujeitos pesquisados consideram relevantes metodologias de ensino que utilizam as tecnologias digitais para contribuir com a interação e o aprendizado dos estudantes das escolas e identificam que sua elaboração demanda um trabalho diferenciado e organizado.

No entanto, apesar dos registros acima, os bolsistas pesquisados, mesmo imersos em um ambiente com alto nível tecnológico como o LIFE, construíram os materiais utilizando os recursos que a escola tinha. Pouco exploraram recursos, além da lousa digital, do projetor, do notebook e do tablet. A filmadora não foi usada, nem tampouco, a mesa interativa e outros equipamentos que estão à disposição do LIFE.

Nessa categoria buscou-se analisar indicadores como criação, criatividade e exploração de diferentes recursos tecnológicos, diante de discussões anteriores sobre o perfil do professor do século XXI. Pode-se identificar que houve produção de materiais em diferentes níveis: alguns se desafiaram e produziram e-books, blogs, objetos de aprendizagens, vídeos com as falas das crianças, discussão e produções de charges, explorando a interatividade e coautoria dos estudantes da escola. Outros se limitaram a transpor um conteúdo didático, de uma tecnologia tradicional 
(quadro) para a o projetor multimídia. Considera-se que o desenvolvimento desse tipo de material pedagógico se diferencia, pois explora imagens, esquemas e outros recursos visuais, mas a sua exploração didática continua a ser do mesmo modo, com um emissor e vários receptores, não explorando a potencialidade das tecnologias digitais para modificar a comunicação, interação e especialmente o protagonismo. O que se percebe é uma concepção de "educação bancária" (FREIRE, 2014). A questão que fica é: essa prática pedagógica é inovadora? Qual será o protagonismo dos estudantes da educação básica com o material produzido? Quais os sentidos de usar tecnologias digitais nas práticas pedagógicas?

Outra categoria de análise foi identificar as dificuldades para a não utilização das tecnologias digitais nas práticas de docência no PIBID e dificuldades na produção dos materiais digitais, em que os bolsistas apontam:

"Recursos tecnológicos escassos em algumas realidades escolares";

"Falta de organização de registros durante as atividades propostas com as crianças para compor o vídeo produzido";

"Falta de tempo";

"Dificuldade na reserva da sala de informática nas escolas".

Conforme o diário de aula e a primeira categoria de análise, os bolsistas reconhecem a importância do uso das tecnologias digitais no processo de aprendizagem. Mas percebe-se uma distância entre as práticas discursivas e a utilização delas nas práticas do PIBID propostas e desenvolvidas nas escolas.

Um dos motivos da distância é pelas escolas não disporem de equipamentos tecnológicos e quando têm acesso a eles, são equipamentos que já estão desatualizados ou mesmo possuem um número inferior ao número de estudantes das escolas, como é o caso de salas informatizadas, projetores multimídias e programas que demandam computadores mais atualizados e com maior capacidade de processamento e armazenamento.

No entanto, uma das alternativas dos professores seria aproveitar os equipamentos móveis que os estudantes possuem para explorar conteúdos virtuais 
ou mesmo produzir materiais, como por exemplo, a produção de um vídeo/áudio. Mas essas sugestões não apareceram como propostas pelos sujeitos pesquisados.

Outro motivo analisado em relação à segunda categoria é o registro como modo de reflexão e a avaliação de práticas pedagógicas e de estudantes por meio das tecnologias digitais. Sua prática é pouco explorada ou utilizada superficialmente entre professores em formação, o que dificulta a sistematização desses recursos tecnológicos. A falta de tempo também justifica a ausência do registro. Diante dos relatos, reafirma-se que o cotidiano da profissão é marcado por tarefas institucionais escolares, como o preenchimento de documentos, participações em reuniões e o envolvimento com eventos festivos e reservas de espaço, fazendo com que outros movimentos, como o registro das aulas seja um trabalho realizado nas brechas entre as várias atividades ou não realizado.

Com base nas práticas discursivas dos bolsistas acerca das percepções e das dificuldades, é possível perceber que eles destacam a importância de trabalhar com as tecnologias digitais, mas na formação inicial não tem tempos e espaços para aprofundar a discussão bem como para vivenciar práticas pedagógicas que utilizam as tecnologias digitais.

Segundo os dados coletados nas matrizes, nos planos de ensinoaprendizagem e na utilização do Ambiente Virtual de Aprendizagem ${ }^{1}$, na maioria dos cursos de formação de professores não há disciplinas que discutem e ensinam a produzir com as tecnologias digitais. E, com relação à utilização das tecnologias digitais pelos professores da instituição, percebe-se, pela fala dos bolsistas, que se usa apenas o que é obrigatório, como o preenchimento virtual da frequência e avaliação, e explora-se o Ambiente Virtual de Aprendizagem sobretudo como depositório de materiais. Outro dado da formação inicial é que apesar do LIFE estar à disposição dos cursos de Licenciatura, sua maior utilização tem sido pelos programas PIBID e PARFOR. Os bolsistas PIBID passam a conhecer o LIFE através das oficinas do PIBID, promovidas pela Gestão do Programa na IES, e não pelos Coordenadores de Área. Os bolsistas que participaram da oficina também não conheciam o espaço a partir de suas aulas nos cursos de graduação. Dados que

\footnotetext{
${ }^{1}$ O AVA da FURB é um portal utilizado para realização de atividades como fórum, texto colaborativo,
} postagem de materiais aos acadêmicos e controle de frequência e notas. 
apontam para uma concepção de educação centrada no professor, cujos espaços são depósitos de materiais. A problematização sobre as tecnologias digitais parece não ser elemento do cotidiano na formação dos sujeitos pesquisados.

Os bolsistas também relataram que a internet facilita a obtenção de informações e serve de meio para dar visibilidade aos materiais produzidos. Os bolsistas ainda posicionaram-se argumentando que, com maior interação e interesse nas aulas, assim como com a utilização de vídeos, músicas e imagens, é possível atender aos diversos tipos de aprendizagem dos estudantes das escolas de educação básica.

O grande desafio é fazer com que as tecnologias digitais cheguem às salas de aula como potencializadoras da aprendizagem, e não como parte de um mero processo de substituição de tecnologias. A formação inicial docente e a escola precisam ser pensadas em outros tempos e de outras formas, entendendo que há outros modos de ser, estar, aprender e comunicar-se na contemporaneidade. Trabalhar a formação tanto do professor como do estudante de educação básica exige a construção de outras subjetividades, outros sentidos para as tecnologias digitais e outro sentido para a escola.

Sibilia nos apresenta problematizações como "Quais são os tipos de corpos e subjetividades cuja produção gostaríamos de estimular hoje em dia? Que tipo de escola teríamos que implementar para concretizar tal projeto?" (2012b, p. 197). A autora aponta que as mudanças na escolarização implicam a libertação de velhos mecanismos de ortopedia social para uma sociedade hiperconectada.

A ação pedagógica do professor com as tecnologias digitais vai além de conhecer bem algum recurso ou técnica, mas contribuir para problematizar a formação do estudante na contemporaneidade. Esse tempo é um tempo de desafios e de possibilidades. Nesse contexto, as tecnologias digitais são um meio para potenciar as aprendizagens, por proporcionar multiplicidade de informação, comunicação e, principalmente, de criação. É nesse sentido que as tecnologias digitais podem inovar.

\section{DIALOGANDO COM ALGUNS SENTIDOS}


A pesquisa lidou com uma problemática do tempo presente: o uso das tecnologias digitais na formação inicial. Os dados da pesquisa inferem que apesar das tecnologias digitais terem invadido os escolares, invadiram as escolas, mas ainda não invadiram as práticas pedagógicas nas escolas, tanto no sentido de problematizar as tecnologias digitais e seu uso como no sentido de utilizá-las nos processos de construção do conhecimento.

Os dados trazem a distância que a formação inicial e a escola de educação básica têm na utilização das tecnologias digitais nos processos de aprendizagem. As práticas discursivas apontam para o papel e a relevância das tecnologias digitais nos processos de ensino-aprendizagem. Mas, na organização das práticas dos bolsistas do PIBID, população pesquisada, as tecnologias digitais não aparecem ou aparecem pouco, e quando aparecem são tímidas em seus aspectos potencializadores de aprendizagem. Outro dado que a pesquisa trouxe é que se não fosse o projeto desenvolvido pelo PIBID, o LIFE não seria sequer conhecido pelos bolsistas dos cursos de licenciatura da Universidade pesquisada. Já nas escolas, segundo os sujeitos pesquisados, as dificuldades para acesso e utilização das tecnologias digitais são muitas, dentre elas equipamentos e espaços.

Acredita-se que a formação de professores (inicial e continuada) para esse tempo exige tempos e espaços para estudar, problematizar, registrar, utilizar e criar com as tecnologias digitais. Lembrando que "em um mundo de produção customizada, de inovação e de atualizações contínuas e de ciclos de vida de produto cada vez mais breves, tudo se torna quase imediatamente desatualizado" (SIBILIA, 2002, p. 27).

O artigo, ao problematizar, pretende apenas servir de diálogo para que possamos aprender, ler e conhecer os sentidos das tecnologias digitais para os estudantes das licenciaturas, futuros professores. As complexidades da escola e da sala de aula não se resolvem com ou sem as tecnologias digitais, a escola sempre esteve e sempre estará utilizando tecnologias tanto para disciplinar como para controlar. O que se discute são possibilidades de com ou sem as tecnologias digitais potencializarmos os movimentos de aprendizagem, em que a produção esteja também com o estudante, que ele possa ser protagonista e deixe definitivamente de ser ALUNO! Não só deixe de ser chamado de aluno, mas de ser pensado, visto e 
tratado como aluno nas práticas pedagógicas.

Canário (2006) coloca uma questão que contribui para pensarmos as práticas escolares: como é que os professores e os estudantes podem interagir no sentido de serem produtores de saber? As tecnologias digitais, pelo seu modo de distribuição, organização e possibilidades, podem contribuir nesse aspecto? Acredita-se que uma outra estética pode alterar formas consolidadas das práticas escolares, podendo trazer outra cultura sobre a escola, sobre ser professor, sobre formação e para outro tempo. Uma estética que supere as formas de fazer escola consolidadas desde a modernidade e pouco alteradas. Um outro sentido para a escola.

Com esta pesquisa foi possível problematizar os sentidos das tecnologias digitais na formação inicial de professores. A participação dos bolsistas das licenciaturas na formação no LIFE oportunizou a eles conhecerem recursos tecnológicos inovadores de comunicação e interação, bem como, as socializações dos materiais produzidos proporcionaram com que os grupos conhecessem as produções e os trabalhos desenvolvidos nas outras escolas de cada grupo do PIBID, resultando em um momento de troca de experiências pedagógicas, de diálogo, de possibilidades de formação de coletivos que possam pensar a escola. Mas trouxe alguns questionamentos: em que medida as práticas se distanciam de concepções bancárias de educação?

As tecnologias digitais estão nas escolas, disso não temos dúvidas, mas o que estão produzindo? Em que medida estão trazendo inovação para as práticas escolares e em que medida são apenas mais uma tecnologia para mantermos os corpos disciplinados e ocupados? Em que medida são apenas mais uma tecnologia para transformar a cada um e a todos em "bons gestores"? (CERVI, 2013). Em que medida são possibilidades de autonomia, de emancipação, de uma outra estética e de construção de coletivos? Essas e outras questões não foram possíveis de responder neste artigo, mas abrem-se portas para outras pesquisas sobre o PIBID e as tecnologias digitais para ampliarmos a discussão sobre o tema.

Com Certeau (1994), compreendemos que o cotidiano é múltiplo e multifacetado e que o uso pelos praticantes dos produtos/artefatos culturais se dá gerando variadas práticas e criando conhecimentos, permanentemente. E, nesse sentido, o uso das tecnologias digitais no PIBID cria conhecimentos 
permanentemente. As práticas no PIBID têm gerado permanentemente conhecimentos sobre os sentidos das tecnologias digitais na formação inicial e continuada e na escola, como também sobre os sentidos da escola. Talvez possibilidades de criar para "alguns" outro sentido para a escola.

\section{GICELE MARIA CERVI}

Doutora em Ciências Sociais pela Pontifícia Universidade Católica de São Paulo (PUC-SP). Professora do Departamento de Educação e do Mestrado em Educação da Universidade Regional de Blumenau (FURB). Coordenadora Institucional do PIBID - FURB.

\section{JULIANA FAVERE}

Mestre em Educação. Professora do Departamento de Educação da Universidade Regional de Blumenau (FURB). Coordenadora de Gestão do PIBID - FURB.

\section{REFERÊNCIAS}

BRASIL. Integração das Tecnologias na Educação/ Secretaria de Educação a Distância. Brasília: Ministério da Educação- MEC, Seed, 2005, 204 p.

CAPES - COORDENAÇÃO DE APERFEIÇOAMENTO DE PESSOAL DE NÍVEL SUPERIOR. Regulamento do Programa Institucional de bolsa de iniciação à Docência. Portaria nº 096, de 18 de Julho de 2013, 24p.

CANÁRIO, R. A escola tem futuro? Das promessas as incertezas. Porto Alegre: Artmed, 2006, 160p.

CERTEAU, M. Invenção do cotidiano: as artes de fazer. Petrópolis, RJ: Vozes, 1994, $351 \mathrm{p}$.

CERVI, G. M. Política de Gestão na Sociedade de Controle. Rio de Janeiro: Achiamé, 2013, 206 p.

COSTA, S. R. Leitura e escritura de hipertextos: implicações didático-pedagógicas e curriculares. Veredas: revista de estudos linguísticos, Juiz de Fora, v.4, n. 1, p. 4349, jan./jun. 2000.

DELEUZE, G. Conservações. 7. ed. São Paulo: Editora 34, 2008, 240 p.

; GUATTARI, F. Mil platôs: capitalismo e esquizofrenia. Rio de Janeiro: Editora 34, 1995, 128 p. 
FEITOSA, A. V. N.; SOUSA, M. A. S.; ANDRADE, M. J. P. A utilização de vídeos educativos e o youtube na prática pedagógica. In: XIII Jornada de Ensino, Pesquisa e Extensão, Universidade Federal Rural Pernambuco (UFRP): Recife, dez. 2013, 3 p.

FOUCAULT, M. Vigiar e Punir. 39. ed. Petrópolis: Vozes, 2011, 262 p.

FREIRE, P. Pedagogia do oprimido. 56. ed. Rio de Janeiro: Paz e Terra, 2014, 256 p.

GOMEZ, M. Cibercultura, formação e atuação docente em rede: guia para professores. Brasília: Liberlivro, 2010, 150 p.

LÉVY, P. Cibercultura. São Paulo: Editora 34, 2011, 264 p.

MAGNABOSCO, G. G. Gêneros Digitais: modificação na e subsídio para a Leitura e a Escrita na Cibercultura. Revista Prolíngua. Paraíba, v.2 n. 1, p. 90-101, jan./jun. 2009.

MASSCHELEIN, J.; SIMONS, M. Em defesa da escola: Uma questão pública. Belo Horizonte: Autentica, 2013, 176 p.

MOSÉ, V. A escola e os desafios contemporâneos. 3. ed. Rio de Janeiro: Civilização Brasileira, 2014, $336 \mathrm{p}$.

SIBILIA, P. Redes ou paredes: A Escola em tempos de dispersão. Rio de Janeiro: Contrapontos, 2012a, 222 p.

. A escola no mundo hiperconectado: Redes em vez de paredes? Matrizes, São Paulo, v. 5, n. 2, p. 195-211, jan./jun. 2012b.

O Homem pós-orgânico: corpo, subjetividade e tecnologias digitais. Rio de Janeiro: Relume Dumará, 2002, 228 p.

SILVA, M. Sala de aula interativa: educação, comunicação, mídia clássica, internet, tecnologias digitais, arte, mercado, sociedade e cidadania. 5. ed. São Paulo: Loyola, 2010, 269 p.

. Formação de Professores para a Docência Online. Actas do X Congresso Internacional Galego-Português de Psicopedagogia. Braga: Universidade do Minho, 2009, p. 25 - 40.

; CLARO, T. A docência online e a pedagogia da transmissão. B. Téc. Senac: a R. Educ. Prof. Rio de Janeiro, v. 33, n.2, p. 81-89, mai./ago. 2007.

SOARES, M. Novas práticas de Leitura e Escrita: letramento digital. Educação e Sociedade, Campinas, v. 23, n. 81, p. 143-160, dez. 2002. 
Atos de Pesquisa em Educação - ISSN 1809-0354

Blumenau, v. 10, n.2, p.479-503, mai./ago. 2015

DOI: http://dx.doi.org/10.7867/1809-0354.2015v10n2p479-503 503

VEEN, W. ; VRAKKING, B. Homo zappiens: educando na era digital. Porto Alegre: Artmed, 2009, $141 \mathrm{p}$. 